\title{
CORRESPONDENCE
}

\section{RADIO TECHNIQUES FOR THE MEASUREMENT OF ICE THICKNESS}

It has come to my attention that measurement of glacier thickness by radio methods (as distinct from direct-current electrical methods) was attempted with some success as early as 1927. W. Stern, of the Department of Geophysics, University of Göttingen, published a paper "Principles, Methods, and Results of Electrodynamic Thickness Measurement of Glacier Ice" in Zeitschrift für Gletscherkunde, Leipzig, Vol 18, 1930, p 24. The following summary of his work should be added to the article on this subject in the Polar Record, Vol 11, No 73, 1963, p 406-10.

Stern considers two possible techniques. The first is to observe interference phenomena between waves which have travelled directly over the surface of a glacier from a radio transmitter to a receiver, and those which have travelled down through the glacier and been reflected at the bottom surface. He remarks that the solution of the problem is laborious, and possibly ambiguous, if the bottom surface is not parallel to the top, and he fails to allow for the difference in velocity of the two waves. He expects the attenuation of the wave passing through the ice to be negligible, based on knowledge of the direct-current electrical conductivity of glacier ice and, for the depths with which he is concerned and the radio frequencies which could be generated in 1927, this is true. Unfortunately, the method was not tried in the field owing to lack of funds, but it may yet be the only one suitable for the thickest parts of the Antarctic ice sheet.

The second method which he considers is based on the capacity of a wire laid on the surface of the glacier which in turn lies on a more highly conducting layer of soil. Changes in the capacity are measured by changes in the resonant length of the wire used as a transmitting antenna at a frequency of about $1 \mathrm{Mc} / \mathrm{s}$. The method was used on the Hochvernagtferner in 1927 and 1928 and depths up to $40 \mathrm{~m}$ were measured. He calls them "proportional depths" because it is found necessary to start at some point where the depth is known and this is accomplished by plumbing a crevasse, evidently with a very uncertain result. The armchair critic would expect the whole method to be fraught with uncertainty because of unknown electrical capacities introduced by objects in the vicinity, in addition to the ground beneath the glacier. However, the apparatus required was simpler than for the much more promising interference method.

I am greatly indebted to Terence Armstrong for translation of Stern's paper from the German.

S. EVANS

SCOTT POLAR RESEARCH INSTITUTE

CAMBRIDGE

10 June 1963 